\title{
The impact of rural residence and HIV infection on poor tuberculosis treatment outcomes in a large urban hospital: a retrospective cohort analysis
}

\author{
Aishatu Lawal Adamu ${ }^{1,2^{*}}$ D, Muktar H. Aliyu $u^{3,4}$, Najiba Aliyu Galadanci ${ }^{5}$, Baba Maiyaki Musa ${ }^{6}$,
} Umar Muhammad Lawan ${ }^{1,2}$, Usman Bashir ${ }^{1,2}$ and Ibrahim Abubakar ${ }^{7}$

\begin{abstract}
Background: Successful tuberculosis (TB) treatment is essential to effective TB control. TB-HIV coinfection, social determinants and access to services influenced by rural residence can affect treatment outcome. We examined the separate and joint effects of rural residence and HIV infection on poor treatment outcome among patients enrolled in a large TB treatment centre in Kano, Nigeria.

Methods: We retrospectively analysed a cohort of patients with TB enrolled in a large urban TB clinic in northern Nigeria, from January 2010 to December 2014. Poor treatment outcome was defined as death, default or treatment failure. We used Poisson regression to model rates and determine the relative risks (and 95\% confidence intervals, Cl) of poor treatment outcomes.

Results: Among 1381 patients included in the analysis, 28.4\% were rural residents; 39.8\% were HIV-positive; and $46.1 \%$ had a poor treatment outcome. Approximately 65 and 38\% of rural and urban residents, respectively, had a poor treatment outcome. Rural residents had 2.74 times (95\% Cl: 2.27-3.29) the risk of having a poor treatment outcome compared to urban residents. HIV-positive patients had 1.4 times (95\% Cl: 1.16-1.69) the risk of poor treatment outcome compared to HIV-negative patients. The proportion of poor treatment outcome attributable to rural residence (population attributable fraction, PAF) was 25.6\%. The PAF for HIV infection was $11.9 \%$. The effect of rural residence on poor treatment outcome among HIV-negative patients (aRR:4.07; 95\%Cl:3.15-5.25) was more than twice that among HIV-positive patients (aRR:1.99; 95\%Cl:1.49-2.64).

Conclusion: Rural residents attending a large Nigerian TB clinic are at increased risk of having poor treatment outcomes, and this risk is amplified among those that are HIV-negative. Our findings indicate that rural coverage of HIV services may be better than TB services. These findings highlight the importance of expanding coverage of TB services to ensure prompt diagnosis and commencement of treatment, especially among rural-dwellers in resource-limited settings.
\end{abstract}

Keywords: Tuberculosis, Nigeria, Treatment outcome, Poor treatment outcome, Rural residence, HIV

\footnotetext{
* Correspondence: aladamu.cmed@buk.edu.ng

'Department of Community Medicine, College of Health Sciences, Bayero

University Kano, Kano, Nigeria

${ }^{2}$ Department of Community Medicine, Aminu Kano Teaching Hospital, Kano,

Nigeria

Full list of author information is available at the end of the article
}

(c) The Author(s). 2018 Open Access This article is distributed under the terms of the Creative Commons Attribution 4.0 International License (http://creativecommons.org/licenses/by/4.0/), which permits unrestricted use, distribution, and reproduction in any medium, provided you give appropriate credit to the original author(s) and the source, provide a link to the Creative Commons license, and indicate if changes were made. The Creative Commons Public Domain Dedication waiver (http://creativecommons.org/publicdomain/zero/1.0/) applies to the data made available in this article, unless otherwise stated. 


\section{Background}

Effective tuberculosis (TB) control is largely dependent on successful treatment. Between 2000 and 2014, 43 million deaths were prevented through effective TB treatment and global TB deaths have declined by almost half from 1990. [1] Despite this progress, each year over 1 million deaths from TB occur and about 3.6 million people with TB are still missed by health systems annually and therefore fail to receive appropriate care. [2] The importance of identifying sub-groups with high risk of TB and its consequences has been emphasised. [3, 4] The End TB Strategy recognises the need to address underlying social determinants (poverty, food insecurity, poor living and working conditions) and consequences (catastrophic economic costs, stigmatisation, social isolation, loss of job and divorce) of TB to effectively control the disease. [5-7] HIV infection, one of the major drivers of TB burden in sub-Saharan (SSA) also complicates diagnosis and treatment of TB, and is associated with poorer treatment outcomes, such as treatment failure and death. Early diagnosis and prompt initiation of treatment with anti-tuberculous medications reduce infectiousness, transmission, deaths and other poor outcomes, including treatment failure and drug resistance.

Nigeria is a high burden country with regards absolute number of TB cases, TB-HIV co-infection and multidrug resistance. [8] An estimated 586,000 new TB cases (322/100,000 population) and 240,000 TB-related deaths occur in Nigeria yearly. [9] TB control in Nigeria is managed by the TB and Leprosy Control Programmes operating at the three levels of healthcare. [10] TB in Nigeria is largely externally funded through the Global Fund to fight AIDS, TB and Malaria (GFATM), and the United States Agency for International Development (USAID) through Challenge TB; and to a lesser extent domestically, with persistent funding gaps especially at lower government levels. [11-13] TB treatment and microscopy services are provided free across treatment centres and microscopy sites in the country, [14] with lower coverage in the northern states. [11] TB services are also disproportionately distributed in favour of urban areas, [14] potentially leaving a larger proportion of people from rural areas with poor access to TB care. Geographic barriers related to rural living influence access to TB care and clinical outcomes. [3] Additionally, individual risk factors of rural residents such as low educational attainment and income can influence careseeking behaviours, resulting in treatment delays and poor treatment adherence. [15] Poor access to health care could also lead patients to seek less credible alternative care. [16] Though urban residence is a recognised risk factor for TB, especially in rapidly urbanising communities due to poor living conditions, [3] the gap in TB services coverage between the northern and southern part of the country, as well as between the rural and urban areas may have worsened inequalities to treatment access which can affect the treatment outcome. In addition to providing specialist services such as diagnosis of extra-pulmonary and smear-negative TB, several tertiary-level facilities in the country (which are largely urban-based) also provide primary care services, such as diagnosis and treatment of pulmonary TB. This imbalance may also further worsen rural-urban inequalities in TB care. Establishing the effect of rural residence in the context of the country with the 4th largest global burden of TB and gross inequalities in TB services, while adjusting for confounding factors, which previous studies have not always done, provides important policy-relevant information.

Due to high TB-burden and disproportionately distributed TB services in Nigeria, we anticipate that a substantial number of people in rural areas would need to access care in large treatment centres within cities. The aim of this analysis was to describe treatment outcomes and examine the impact of rural residence and HIV infection on poor treatment outcomes among TB patients attending a large urban treatment centre. Our hypothesis is that rural residents who travel to access care in urban centres have a higher risk of poor TB treatment outcome, and this risk is modified by their HIV status. [3]

\section{Methods \\ Study population}

Data from patients age $\geq 15$ years and enrolled in Aminu Kano Teaching Hospital (AKTH) TB clinic for TB treatment between 2010 and 2014 were included in this analysis. A total of 43 (2.9\%) of 1424 patients that were transferred to another treatment centre were excluded. Patients diagnosed with $\mathrm{TB}$ received treatment based on the existing national TB treatment guidelines. $[17,18]$ Recommended treatment duration was either 8 months (up to 2012) or 6 months (from 2013), except for some cases of extrapulmonary TB - spine and central nervous system (CNS), where treatment is longer. Treatment comprised four drugs - Rifampicin (R), Isoniazid $(\mathrm{H})$, Pyrazinamide $(Z)$ and Ethambutol $(E)$ in the 2-month intensive phase; and two drugs in the continuation phase- either Ethambutol and Isoniazid (up to 2012) or Rifampicin and Isoniazid (from 2013 onwards). Before drug susceptibility testing became available in the hospital (2014 onwards), treatment regimen for re-treatment patients comprised 3-month intensive phase with RHZE with Streptomycin added in the first 2 months; and 5-month continuation phase with RHE. Patients enrolled in the clinic included presumed and confirmed TB cases referred from the same hospital or other hospitals within and outside Kano. TB/HIV services are co-located and patients are routinely counselled and screened for HIV, if their HIV status is unknown. 


\section{Study design}

This study was a retrospective cohort design that included patients who commenced TB treatment from January 2010 to December 2014. Cohort entry was defined as the date of treatment initiation. Cohort exit was defined as the first to occur from: treatment completion, death prior to treatment completion, treatment failure and loss to follow-up. Follow-up time was ordered by time since treatment initiation, and tracked as person-months (pm).

Data on independent variables and treatment outcome were collected from clinic-based records. Information available from the records included: date of treatment onset, age, sex, place of residence, mode of diagnosis, disease site, referral source, HIV status at treatment onset, history of previous TB treatment and treatment outcome. Medication intake was observed in the clinic once a week during the intensive phase, and once a month during the continuation phase. Daily supervision of medication intake was performed by an assigned family member. Data on independent variables were not updated during follow-up. Site of disease was grouped as pulmonary (disease affecting lungs only), extra-pulmonary (disease affecting organs other than the lung) and both (disease affecting the lungs and any other organ). The rationale for grouping the disease site into three and not as done in the National guidelines (where patients with both pulmonary and extrapulmonary TB are classified as pulmonary TB), was to allow us to account for disease severity, as patients with TB involving 2 or more organs tend to have more severe disease. Mode of diagnosis was grouped as bacteriologically-diagnosed (sputum-smear or culture confirmed) or clinically diagnosed (smear-negative and physician-diagnosed using clinical features with radiological and/or other laboratory evidence and a decision to treat with at least 6 months anti-TB therapy).

The outcome variable was poor treatment outcome, which was a composite measure comprising death from any cause including deaths from TB among HIV-positive persons; treatment failure from lack of conversion or reversion; and loss to follow-up (LTF) from interruption of treatment for two consecutive months or more. [19-22] Outcome was ascertained for $97 \%$ of the patients.

The primary exposure variables were: place of residence, classified as urban (for patients residing in Kano city) and rural (for patients residing outside Kano city); and HIV status as at time of treatment onset, classified as HIV-positive, HIV-negative and unknown HIV status.

\section{Statistical analysis}

We summarised categorical variables using frequencies and proportions. We described the distribution of explanatory variables in the whole study population and stratified by treatment outcome status. We also described the distribution of all potential confounders across strata of primary exposures (residence and HIV). Univariable analysis was performed by cross-tabulating independent variables with treatment outcome, and association assessed one at a time using chi-squared test.

We examined association between poor treatment outcome and exposure variables (residence and HIV) using Poisson regression models. Age, sex and year of treatment onset were denoted as forced variables and a priori included in the model. Variables that were associated with the outcome after adjusting for age, sex and calendar year at $p<0.2$ were included in the multivariable analysis. A multivariable model was built in a forward stepwise manner, one variable at a time. Potential confounders were added sequentially and were retained in the model if they notably changed the effect estimate (relative risk, RR) by at least $10 \%$.

We estimated the population attributable fraction (PAF) of rural residence and HIV status from the final multivariate model by using the standard formula:

$$
\operatorname{PAF}=\mathrm{p}^{\prime}(\theta-1) / \theta
$$

where p' denotes the respective proportions of persons with poor outcome who were rural residents or HIV-positive and $\theta$ represents the relative risks (RR) from the multivariable model.

We also examined for interaction between HIV status and rural residence and between sex and rural residence by fitting an interaction term in the multivariable models. We used a likelihood ratio test to compare the model with and without interaction and presented stratum-specific estimates.

All analyses were performed using Stata 14 (Stata Corp, College Station, TX, USA). This study was approved by the Institutional Review Board of Aminu Kano Teaching Hospital, Nigeria.

\section{Results}

We analysed data on 1381 TB cases enrolled between January 2010 and December 2014. More than two-thirds of the participants were between 15 and 44 years at the time of treatment commencement. More than half (56.8\%) were males. Pulmonary disease was the most common form of $\mathrm{TB}$ in participants (65.7\%). Common extrapulmonary sites comprised the abdomen, spine, and the CNS. Other less common sites included the skin, larynx and adrenals. At the time of treatment commencement, $392(28.4 \%)$ patients were rural residents and 550 (39.8\%) were co-infected with HIV, of which only 90 (16.4\%) were on anti-retroviral treatment (ART). The distribution of age, HIV status, sex, and TB site of the 43 excluded patients were similar to those included in this analysis. However, the patients excluded were more 
likely to be rural residents (41.9\%), and less likely to have a history of prior TB (4.7\%).

Nearly half of the patients $(46.1 \%)$ had a poor treatment outcome after a total follow-up time of 6377.2 person-months (pm), giving a rate of 9.9/100 pm (95\% CI: 9.2-10.8). Of the 636 patients with poor outcome, $57.5 \%$ were lost to follow-up, $37.3 \%$ died during treatment, and $5.2 \%$ failed treatment.

Crude analysis showed that nearly two-thirds (65.3\%) of the rural residents had a poor treatment outcome of treatment, compared to $38.4 \%$ of urban residents. When poor outcome was further broken down to specific

Table 1 Crude association between poor treatment outcome and potential confounders, TB clinic, Aminu Kano Teaching Hospital, Kano, Nigeria

\begin{tabular}{|c|c|c|c|c|}
\hline \multirow[t]{2}{*}{ Variable } & \multirow[t]{2}{*}{ Total (\%) } & \multicolumn{2}{|c|}{ Poor outcome } & \multirow[t]{2}{*}{$P$ value $\left(X^{2}\right)$} \\
\hline & & Yes (\%) & No (\%) & \\
\hline \multicolumn{5}{|l|}{ Age group (years) } \\
\hline $15-24$ & 252 & $91(36.9)$ & $159(63.1)$ & \\
\hline $25-34$ & 382 & $169(44.2)$ & $213(55.8)$ & \\
\hline $35-44$ & 323 & $139(43.0)$ & $184(57.0)$ & \\
\hline $45-54$ & 181 & $105(58.0)$ & $76(42.0)$ & \\
\hline $55-64$ & 82 & $45(54.9)$ & $37(45.1)$ & \\
\hline$>65$ & 70 & $44(62.9)$ & $26(37.1)$ & $<0.001$ \\
\hline \multicolumn{5}{|l|}{ Sex } \\
\hline Female & 785 & $259(43.5)$ & $337(56.5)$ & \\
\hline Male & 596 & 377 (48.0) & $408(52.0)$ & 0.005 \\
\hline \multicolumn{5}{|l|}{ Residence } \\
\hline Urban & 989 & $380(38.4)$ & 609 (61.6) & \\
\hline Rural & 392 & $256(65.3)$ & $136(34.7)$ & $<0.001$ \\
\hline \multicolumn{5}{|l|}{ Referral facility } \\
\hline DOTS-linked facility & 611 & $245(40.1)$ & $366(59.9)$ & \\
\hline Non DOTS-linked facility & 710 & $371(52.3)$ & $339(47.7)$ & $<0.001$ \\
\hline \multicolumn{5}{|l|}{ TB confirmation } \\
\hline Bacteriological & 461 & $126(27.3)$ & $335(72.7)$ & \\
\hline Clinical & 920 & $510(55.4)$ & $410(44.6)$ & $<0.001$ \\
\hline \multicolumn{5}{|l|}{ TB site } \\
\hline Pulmonary & 912 & 370 (40.6) & $542(59.4)$ & \\
\hline Extra-pulmonary & 220 & $95(43.2)$ & $125(56.8)$ & \\
\hline Both & 213 & $140(65.7)$ & $73(34.3)$ & $<0.001$ \\
\hline \multicolumn{5}{|l|}{ HIV/ART status } \\
\hline HIV- & 662 & $292(44.1)$ & $370(55.9)$ & \\
\hline HIV+ & 550 & $264(48.0)$ & $286(52.0)$ & \\
\hline Unknown HIV status & 169 & $80(47.3)$ & $89(52.7)$ & 0.008 \\
\hline \multicolumn{5}{|l|}{ Previous TB treatment } \\
\hline No & 1041 & $411(39.5)$ & $630(33.8)$ & \\
\hline Yes & 340 & $225(66.2)$ & 115 (33.8) & $<0.001$ \\
\hline
\end{tabular}

treatment outcome, among urban residents, $16.7 \%$ were lost to follow-up, $3.0 \%$ failed treatment and $8.9 \%$ died during treatment. While among rural residents, 13.1\% were lost to follow-up, 2.0\% failed treatment and $46.0 \%$ died. The distribution of explanatory variables across treatment outcomes is shown in Table 1.

Univariable associations between residence and other potential confounders (Table 2) showed that the majority $(81.4 \%)$ of rural residents had a clinical diagnosis, compared to $60.8 \%$ of urban residents. Nearly half $(42.9 \%)$ of

Table 2 Association between participant's residence and covariates, TB clinic, Aminu Kano Teaching Hospital, Kano, Nigeria

\begin{tabular}{|c|c|c|c|}
\hline Variable & Urban (\%) & Rural (\%) & $P$ value $\left(X^{2}\right)$ \\
\hline \multicolumn{4}{|l|}{ Age group (years) } \\
\hline $15-24$ & $196(20.9)$ & $56(15.9)$ & \\
\hline $25-34$ & $291(31.1)$ & $91(25.8)$ & \\
\hline $35-44$ & $237(25.3)$ & $86(24.4)$ & \\
\hline $45-54$ & $114(12.2)$ & $67(19.0)$ & \\
\hline $55-64$ & $56(6.0)$ & $26(7.4)$ & \\
\hline$>65$ & $43(4.6)$ & $27(7.7)$ & 0.002 \\
\hline \multicolumn{4}{|l|}{ Sex } \\
\hline Male & $530(53.6)$ & $255(65.1)$ & \\
\hline Female & $459(46.4)$ & $137(34.9)$ & $<0.001$ \\
\hline \multicolumn{4}{|l|}{ Referral facility } \\
\hline DOTS-linked facility & $484(48.6)$ & $127(33.5)$ & \\
\hline Non DOTS-linked facility & $458(51.4)$ & $252(66.5)$ & $<0.001$ \\
\hline \multicolumn{4}{|l|}{ TB confirmation } \\
\hline Bacteriological & $388(39.2)$ & 73 (18.6) & \\
\hline Clinical & $601(60.8)$ & $319(81.4)$ & $<0.001$ \\
\hline \multicolumn{4}{|l|}{ TB site } \\
\hline Pulmonary & $707(73.4)$ & $205(53.7)$ & \\
\hline Extra-pulmonary & $155(16.1)$ & $65(17.0)$ & \\
\hline Both & $101(10.5)$ & $112(29.3)$ & $<0.001$ \\
\hline \multicolumn{4}{|l|}{ HIV status } \\
\hline HIV- & $475(48.0)$ & $187(47.7)$ & \\
\hline $\mathrm{HIV+}$ & $383(38.7)$ & $167(42.6)$ & \\
\hline Unknown HIV status & $131(13.3)$ & $38(9.7)$ & 0.02 \\
\hline \multicolumn{4}{|l|}{ Previous TB treatment } \\
\hline No & 817 (82.6) & $224(57.1)$ & \\
\hline Yes & $172(17.4)$ & $168(42.9)$ & $<0.001$ \\
\hline \multicolumn{4}{|l|}{ Treatment outcome } \\
\hline Cured & $281(32.9)$ & 47 (13.4) & \\
\hline Treatment completed & $328(38.4)$ & 89 (25.4) & \\
\hline Lost to follow-up & $143(16.7)$ & $46(13.1)$ & \\
\hline Died & $76(8.9)$ & $161(46.0)$ & \\
\hline Treatment failed & $26(3.0)$ & $7(2.0)$ & $<0.001$ \\
\hline
\end{tabular}


rural residents had a history of previous TB treatment compared to $17.4 \%$ of urban residents. The distribution of rural residence was similar $(p=0.14)$ among patients who were HIV-negative (28.3\%), HIV-positive (30.4\%) or had unknown HIV status (22.5\%). (Table 3).

The rate of poor outcome was higher among rural residents $(21.1 / 100 \mathrm{pm} ; 95 \%$ CI:18.7-23.8) than in urban residents $(7.4 / 100 \mathrm{pm} ; 95 \% \mathrm{CI}: 6.6-8.1)$. The rate of poor outcome was also higher among HIV-positive patients $(11.4 / 100$ pm;95\% CI: $10.1-12.8)$ compared to HIV-negative patients $(9.0 / 100 \mathrm{pm} ; 95 \% \mathrm{CI}: 8.0-10.1)$. (Table 4).
In multivariable analysis, after adjusting for age, sex, calendar year, mode of diagnosis, TB site, HIV status, prior $\mathrm{TB}$ history, and referral source, rural residents had 2.74 times (95\% CI:2.27-3.29) the risk of a poor treatment outcome compared to urban residents; while HIV-positive patients had 1.4 times (95\% CI:1.16-1.69) the risk compared to HIV negative patients (Table 4). Using the relative risks from the fully-adjusted model, the estimated PAFs were 25.6 and $11.9 \%$ for rural residence and HIV infection respectively.

We examined the joint effects of HIV infection and sex with place of residence. Within each strata of HIV

Table 3 Association between participant's HIV status on enrolment and covariates, TB clinic, Aminu Kano Teaching Hospital, Kano, Nigeria

\begin{tabular}{|c|c|c|c|c|}
\hline Variable & HIV-negative (\%) & HIV-positive (\%) & HIV status unknown (\%) & $P$ value $\left(X^{2}\right)$ \\
\hline \multicolumn{5}{|l|}{ Age group (years) } \\
\hline $15-24$ & $166(26.8)$ & $58(11.3)$ & $28(18.1)$ & \\
\hline $25-34$ & $181(29.2)$ & $156(30.3)$ & $25(29.0)$ & \\
\hline $35-44$ & $112(18.1)$ & $181(35.2)$ & $30(19.4)$ & \\
\hline $45-54$ & $67(10.8)$ & $86(16.7)$ & $28(18.1)$ & \\
\hline $55-64$ & $46(7.4)$ & $23(4.5)$ & $13(8.4)$ & \\
\hline$>65$ & $48(7.7)$ & $11(2.1)$ & $11(7.1)$ & $<0.001$ \\
\hline \multicolumn{5}{|l|}{ Sex } \\
\hline Male & $395(59.7)$ & $296(53.8)$ & $94(55.6)$ & \\
\hline Female & $267(40.3)$ & $254(46.2)$ & $75(44.4)$ & 0.12 \\
\hline \multicolumn{5}{|l|}{ Referral facility } \\
\hline DOTS-linked facility & $423(63.9)$ & $212(42.8)$ & $75(45.7)$ & \\
\hline Non DOTS-linked facility & $239(36.1)$ & $283(57.2)$ & $89(54.3)$ & $<0.001$ \\
\hline \multicolumn{5}{|l|}{ TB confirmation } \\
\hline Bacteriological & $239(36.1)$ & $172(31.3)$ & $50(29.6)$ & \\
\hline Clinical & $423(63.9)$ & $378(68.7)$ & $119(70.4)$ & 0.11 \\
\hline \multicolumn{5}{|l|}{ TB site } \\
\hline Pulmonary & $406(62.5)$ & $386(72.3)$ & $120(74.5)$ & \\
\hline Extra-pulmonary & $120(18.5)$ & $71(13.3)$ & $29(18.0)$ & \\
\hline Both & $124(19.1)$ & $77(14.4)$ & $12(7.5)$ & $<0.001$ \\
\hline \multicolumn{5}{|l|}{ Residence } \\
\hline Urban & $475(71.8)$ & $383(69.6)$ & $131(77.5)$ & \\
\hline Rural & $187(28.3)$ & $167(30.4)$ & $38(22.5)$ & 0.14 \\
\hline \multicolumn{5}{|l|}{ Previous TB treatment } \\
\hline No & $503(76.0)$ & 395 (71.8) & $143(84.6)$ & \\
\hline Yes & $159(24.0)$ & $155(28.2)$ & $26(15.4)$ & 0.003 \\
\hline \multicolumn{5}{|l|}{ Treatment outcome } \\
\hline Cured & $178(30.7)$ & $116(23.9)$ & $34(24.3)$ & \\
\hline Treatment completed & $192(33.2)$ & $170(35.1)$ & $5(39.3)$ & \\
\hline Lost to follow-up & $81(14.0)$ & $75(15.5)$ & $33(23.6)$ & \\
\hline Died & $111(19.2)$ & $111(22.9)$ & $15(10.7)$ & \\
\hline Treatment failed & $17(2.9)$ & $13(2.7)$ & $3(2.1)$ & 0.006 \\
\hline
\end{tabular}


Table 4 Univariable and Multivariable analyses of effect of rural residence and poor treatment outcome using Poisson regression showing crude and adjusted relative risks (RR) with 95\% Cls, TB clinic, Aminu Kano Teaching Hospital, Kano, Nigeria

\begin{tabular}{lllllll}
\hline & $\begin{array}{l}\text { No with poor } \\
\text { outcome }\end{array}$ & $\begin{array}{l}\text { Person-months } \\
\text { of follow-up }\end{array}$ & $\begin{array}{l}\text { Rate } \\
(95 \% \mathrm{Cl})\end{array}$ & $\begin{array}{l}\text { Crude RR } \\
(95 \% \mathrm{Cl})\end{array}$ & $\begin{array}{l}\text { Minimally-adjusted } \\
\text { RR }(95 \% \mathrm{Cl})^{\mathrm{a}}\end{array}$ & $\begin{array}{l}\text { Fully adjusted } \\
\text { RR }(95 \% \mathrm{Cl})^{\mathrm{b}}\end{array}$ \\
\hline $\begin{array}{l}\text { Residence } \\
\text { Urban }\end{array}$ & 380 & 5163.4 & $7.4(6.6-8.1)$ & 1 & 1 & 1 \\
$\begin{array}{l}\text { Rural } \\
\text { HIV status }\end{array}$ & 256 & 1213.8 & $21.1(18.7-23.8)$ & $3.21(2.71-3.81)$ & $3.43(2.89-4.07)$ & $2.74(2.27-3.29)$ \\
$\quad$ HIV-negative & 292 & 3252.2 & $9.0(8.0-10.1)$ & 1 & 1 & 1 \\
$\begin{array}{l}\text { HIV-positive } \\
\text { HIV status unknown }\end{array}$ & 264 & 2319.3 & $11.4(10.1-12.8)$ & $1.27(1.07-1.50)$ & $1.71(1.43-2.06)$ & $1.40(1.16-1.69)$ \\
\hline
\end{tabular}

adjusted for age, sex and calendar year

badjusted for age sex, calendar year, referral facility, TB confirmation mode, TB site, HIV status, and previous TB treatment status

status and sex, rates of poor outcome were higher in rural residents. However, rates were highest among HIVnegative rural residents and rural women respectively. (Figs. 1 and 2) We found strong evidence of interaction between rural residence and HIV status $(p<0.001)$, and between rural residence and sex. Across strata of HIV status, effect of rural residence was higher among HIVnegative patients and women. (Table 5) Adjusted stratumspecific RRs showed that among HIV negative patients, rural residents had more than 4 times (RR:4.07;95\% CI:3.15-5.25) the risk of poor treatment outcome, while among HIV-positive patients, rural residents had about twice the risk (RR:1.99;95\% CI:1.49-2.64).

\section{Discussion}

In this study, we found high levels of poor treatment outcome among a cohort of patients attending a TB clinic in urban Kano, Nigeria. We show that rural residents have more than twice the risk of having a poor treatment outcome when compared to urban residents, and this relationship is modified by HIV status and sex. HIVpositive patients also have a higher risk of poor treatment outcome compared to HIV-negative patients. Our findings show that rural residents who are HIV-negative are substantially more at risk of poor treatment outcomes than their HIV-positive counterparts. Rural women also have a higher risk of poor treatment outcomes compared to rural men.

We found rural residence to be an independent risk factor for poor TB treatment outcome. Though TB prevalence has been shown to be higher in urban settings, [23] several factors could explain poor treatment outcome among rural residents, including: low individual and household income, lower level of education, limited access to health-care, and

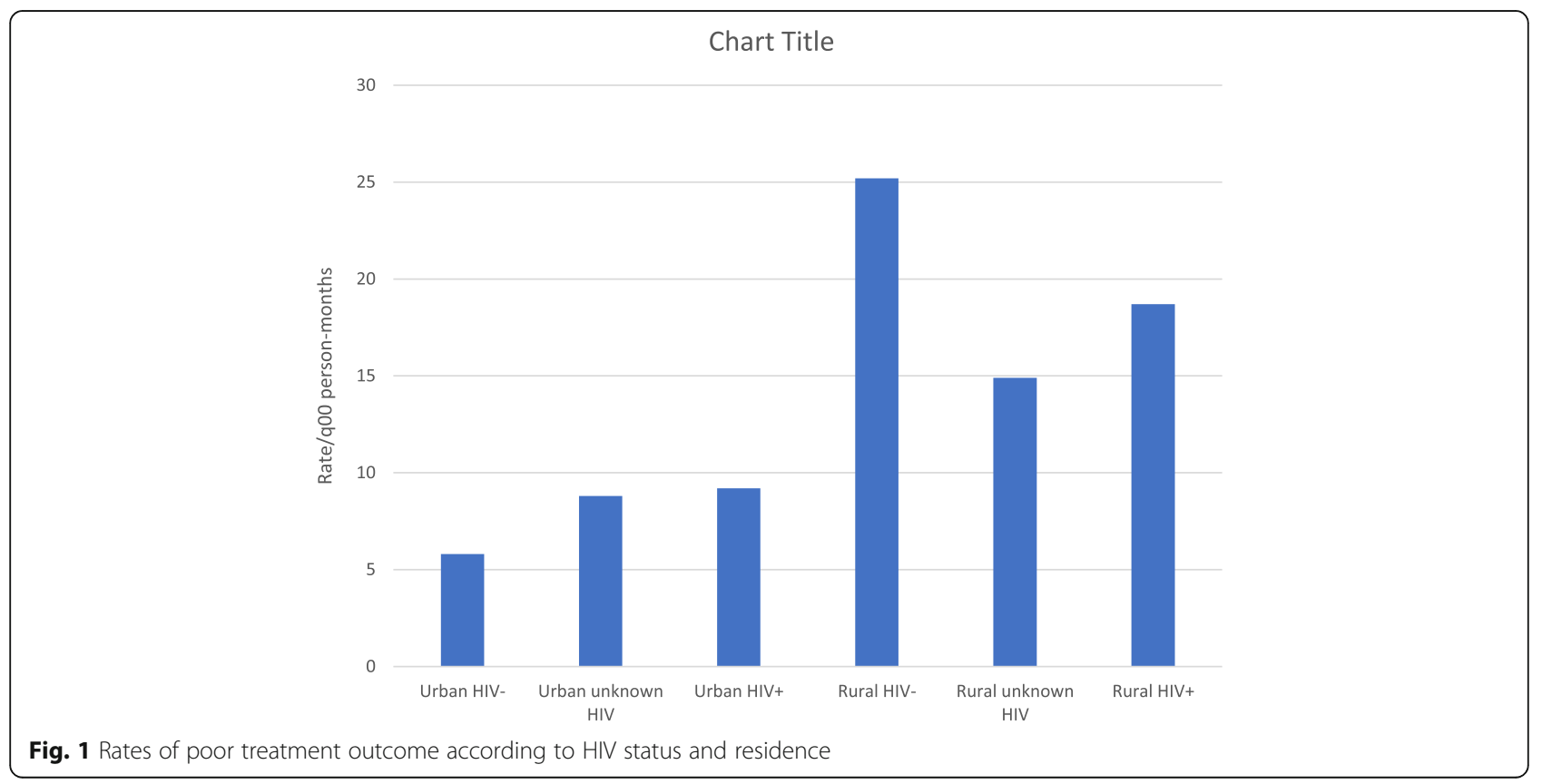




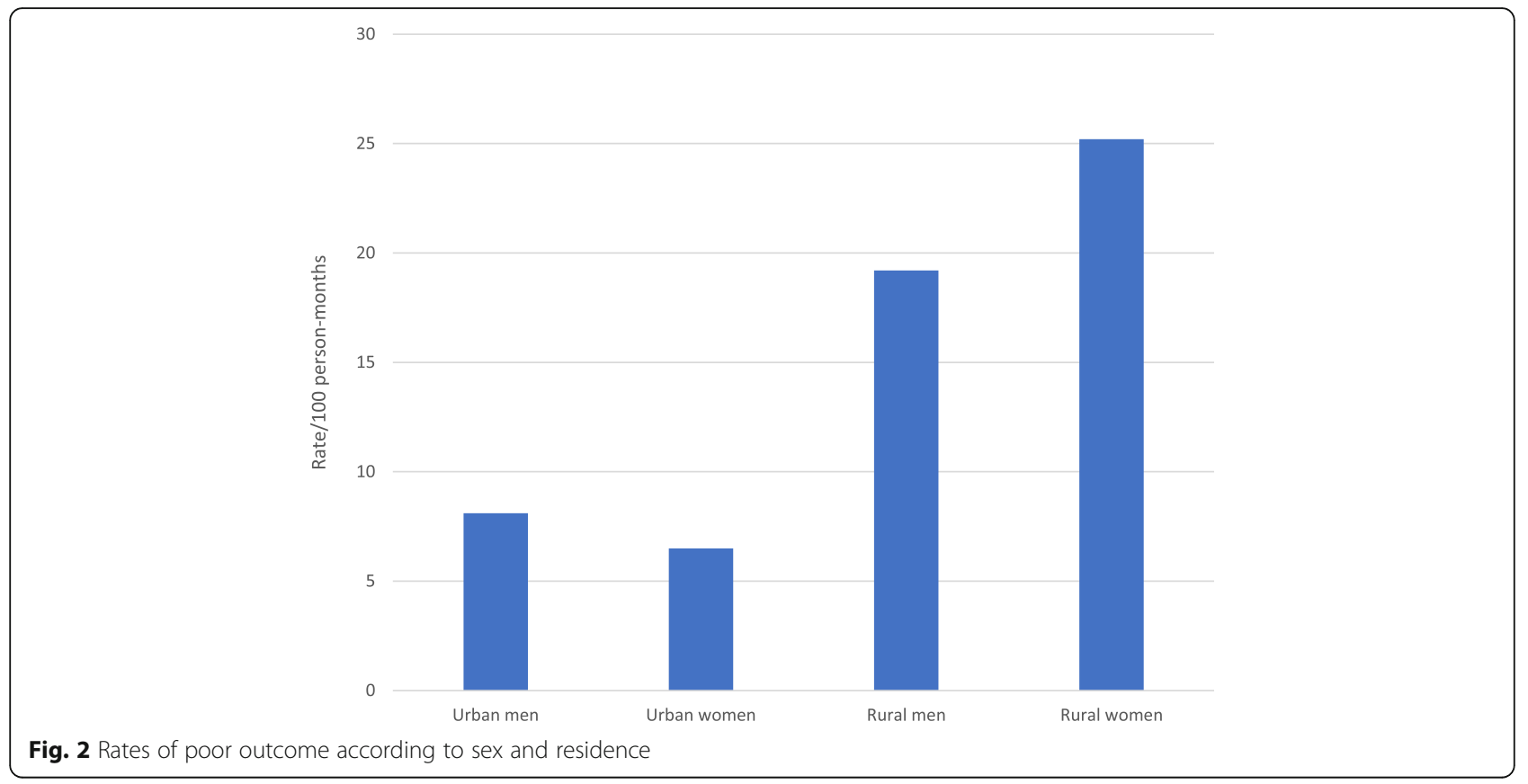

comorbid illnesses. In addition to poor coverage of TB services in rural areas, rural residents may have to incur extra out-of-pocket cost travelling to urban areas to access care. Though drugs and microscopy services are provided free by the National TB programme, hidden costs such as lack of transportation, bad/inaccessible roads, and need for supportive investigations may contribute to poor treatment-seeking behaviour, or cause missed clinic visits. [3, 24] In poor households, especially in rural areas, choices have to be made on how to spend scarce household resources, especially in the presence of competing priorities. [25] Health seeking may therefore be delayed for household members and treatment adherence may be compromised. Lost productivity on days patients have to travel to the city to access care may additionally affect household income. Attitudes including fear of stigma can affect health seeking behaviours and adherence to treatment. [26, 27] Women also have poorer socio-economic status, treatment-seeking behaviours, and healthcare access, and hence higher risk of poor treatment outcomes. [3] Large patient turnout and long waiting periods in large hospitals such as the study

Table 5 Effect of rural residence on poor treatment outcome stratified by HIV-status and sex showing stratum-specific relative risks (RR) with 95\%Cls, TB clinic, Aminu Kano Teaching Hospital, Kano, Nigeria

\begin{tabular}{|c|c|c|c|c|c|}
\hline Variable & Residence & $\begin{array}{l}\text { No with poor outcome/ } \\
\text { person-months }\end{array}$ & $\begin{array}{l}\text { Stratum-specific crude RR for poor } \\
\text { treatment outcome }(95 \% \mathrm{CI})\end{array}$ & $\begin{array}{l}\text { Stratum-specific adjusted RR for } \\
\text { poor treatment outcome }(95 \% \mathrm{Cl})^{\mathrm{a}}\end{array}$ & $\begin{array}{l}P \text {-value for } \\
\text { interaction }(L R T)^{\mathrm{b}}\end{array}$ \\
\hline \multicolumn{6}{|l|}{ HIV status } \\
\hline \multirow[t]{2}{*}{ Negative } & Urban & $159 / 2725.2$ & 1 & 1 & \\
\hline & Rural & $133 / 526.9$ & $4.32(3.44-5.45)$ & $4.07(3.15-5.25)$ & \\
\hline \multirow[t]{2}{*}{ Positive } & Urban & 163/1780.1 & 1 & 1 & \\
\hline & Rural & 101/539.3 & $2.05(1.60-2.62)$ & $1.99(1.49-2.64)$ & \\
\hline \multirow[t]{2}{*}{ Unknown } & Urban & $58 / 658.1$ & 1 & 1 & \\
\hline & Rural & $22 / 147.6$ & $1.69(1.04-2.76)$ & $1.55(0.88-2.73)$ & $<0.001$ \\
\hline \multicolumn{6}{|l|}{ Sex } \\
\hline \multirow[t]{2}{*}{ Male } & Urban & 218/2678.7 & 1 & 1 & \\
\hline & Rural & 159/829.1 & $2.36(1.92-2.89)$ & $2.16(1.71-2.72)$ & \\
\hline \multirow[t]{2}{*}{ Female } & Urban & $162 / 2484.7$ & 1 & 1 & \\
\hline & Rural & $97 / 384.7$ & $3.87(3.01-4.97)$ & $4.08(3.06-5.44)$ & 0.001 \\
\hline
\end{tabular}

adjusted for age, sex, calendar year, referral facility, TB confirmation mode, TB site, HIV status, and previous TB treatment status

${ }^{b}$ Likelihood ratio test 
site may deter patients from seeking care, and has been shown to be associated with treatment default. [28] Such a situation may lead to patients seeking care from unskilled sources and further delay diagnosis and treatment. A TB prevalence survey in Nigeria showed that among suspected TB cases, rural residents were more likely to consult traditional healers while urban residents were more likely to consult pharmacy shops, commonly termed 'chemists'. [23] The use of traditional herbal medications is a recognised risk factor for kidney and liver disease, [29, 30] Traditional herbal medications may also interfere with anti-TB drug metabolism with potential for reducing efficacy. [31] Moreover, traditional healers are more accessible to patients, particularly those residing in rural areas. This preference for non-orthodox health care and relatively easier access to traditional health providers may increase the likelihood of unfavourable treatment outcomes. [28] High levels of poor treatment outcome observed in this cohort could be attributed to the high prevalence of TB/HIV co-infection, poor treatment adherence, delays in diagnosis and treatment, and misdiagnosis. HIV infected persons are more likely to acquire active TB infection and progress to active disease, and those coinfected with TB are more likely to have poor treatment outcomes, [32-34] though ART use may attenuate this risk. [35, 36] Co-infection is associated with disease progression. Adverse drug interactions, coinciding toxicities, and high pill burden in co-infected patients may affect adherence or result in treatment failure. [37] Associated co-morbidities that may increase the risk of poor outcomes are also more frequent among co-infected patients. [3, 36, 38]

When we stratified our data by HIV status, the effect of rural residence among HIV-negative persons was more than twice that among HIV-positive persons. We anticipated their combined effects to be greater than a multiplicative relationship, such that patients who are both rural residents and HIV-positive would have higher risks of poor outcome, since both HIV infection and rural residence are independent risk factors for poor treatment outcome. Surprisingly, HIV-negative rural residents had highest risk of poor treatment outcome. A possible explanation of our findings of negative interaction between rural residence and HIV infection is the relative success of decentralisation of HIV care, including TB-HIV services. [39, 40] This situation may have led to quicker diagnosis and treatment among rural residents who are HIV-positive compared to those who are HIV-negative, attenuating the effect of rural residence among HIV-positive persons. [41] While HIV services are provided by higher-cadre staff, the majority of TB services especially in rural areas are provided by lowercadre health workers, with limited capacity to diagnose smear-negative and extra-pulmonary TB. This may cause delays in $\mathrm{TB}$ diagnosis and treatment that contribute to unfavourable outcomes. Additionally, HIV-negative patients from outside the city may face difficulties in navigating through bureaucracies of referral in a large teaching hospital. Stratifying our data by sex, we also show that effect of rural residence on poor treatment outcomes was higher among women than men. This finding could be related to underlying biological and social vulnerability, including co-morbidities such as anaemia and undernutrition, pregnancy, geographic and socio-cultural barriers to accessing care, and economic dependency. [42-44]

Our findings indicate that rural residents are more likely to have a poor treatment outcome, however, previous investigators have shown varying associations between residence and treatment outcomes. In a UK study, patients living in rural areas were less likely to complete TB treatment compared to urban residents on crude analysis, though the association was confounded by factors such as age, sex, ethnicity, recent immigration to UK and disease site. [21] Crude assessment of TB treatment outcomes in the Solomon Islands from 2000 to 2011 showed almost similar proportions of treatment success among urban and rural areas. [45] Adjusting for age, sex, TB site and year of treatment, a 10-year retrospective analysis of treatment outcomes in Ethiopia showed that patients from rural areas were more likely to have treatment success than those from urban areas. [46] In Zimbabwe, after adjusting for age, sex and HIV-status, urban residents were more likely to have an unfavourable treatment outcome. [22] Hospital-based studies tend to show that rural residence was associated with poor treatment outcomes. [47-49] However, an analysis of treatment outcomes from two treatment centres (urban public and rural private) in southern Nigeria, revealed that poor treatment outcome was associated with receiving care at an urban public health facility. The majority of the patients in the study $(88 \%)$ received care from the private health care facility (rural) and may not necessarily be residing in rural areas. [50] It is possible that our data may be missing milder cases from rural areas and we may have overestimated poor treatment outcome because milder cases are more likely to have better treatment outcomes. However, since our study site is a tertiary hospital which provides specialist care, our data will capture more severe cases irrespective of place of residence and any overestimation of poor treatment outcome will also apply to urban residents.

Assuming a causal relationship and absence of residual confounding, we found that about a quarter of poor outcomes could be averted, if the increased risk associated with rural residence could be eliminated. Decentralisation of $\mathrm{TB}$ care to improve access to rural residents could substantially reduce poor treatment outcomes. 
Our findings have important implications for TB control. Poorer treatment outcomes such as treatment failure and loss to follow-up among rural residents can increase the risks of further transmission within the community; drug resistant TB; and catastrophic economic costs and burden from treatment of disease complications on already impoverished households. More frequent poor outcomes among the younger and probably more economically and physically productive patients could directly affect household income sources and have wider impact on the basic needs of food and healthcare of other vulnerable household members, such as young children and women. $\mathrm{TB} / \mathrm{HIV}$ co-infection has been traditionally recognised as a risk factor for poor TB outcomes. However, following expansion of HIV services which include HIV-TB care, HIV-infected persons may have better access to TB care, including referral and management of other co-morbidities which may improve treatment outcomes. Our results suggest that for patients who have to travel to access TB care in a large treatment centre, being HIV-negative may actually be detrimental to treatment outcomes. We believe our findings are generalizable to many tertiary-level facilities that provide TB care across the country, and therefore the implications could have a much wider impact on TB control in Nigeria.

Our results may be explained by individual sociocultural factors that may influence health and health careseeking among rural residents, however, we believe the contextual effects of rural residence captures effects of both compositional individual-level and group-level factors. $[15,51]$ Due to the retrospective nature of this study, we were limited by information available from the TB registers, and as such we could not account for other measures of disease severity including HIV stage and other comorbid conditions. We may therefore have over-estimated the effect of rural residence on treatment outcome, if rural residents had more severe disease. However, reasons for seeking care at an urban facility may also be related to unavailability of $\mathrm{TB}$ care in rural areas and not only referral for more severe disease. We also did not account for anti-retroviral use among HIV-positive patients, because only ART status at treatment initiation was recorded and was not updated in the patient records if ART was commenced during TB treatment. Thus, we may have over-estimated the effect of HIV infection. It is possible that the patients excluded could have a different risk of poor treatment outcome because they were more likely to be rural residents. However, other characteristics of the excluded patients (age, sex, TB site, HIV status) were similar to those included in this analysis. There may be differences in causes and risk factors for death, loss to follow-up or treatment failure that we may not have captured in our analysis, as we grouped the different sub-categories comprising poor treatment outcome as one. Risk factors for treatment failure reported from previous studies include drug resistance, severity of disease, co-morbidities, positive culture at 2 months $[52,53]$; while low socio-economic status, poor adherence, poor access to health care, substance abuse, fear of stigma, lack of social support, and anti-TB side effects have been implicated in treatment default. [27, 28] However, risk factors for different poor treatment outcomes have also been shown to overlap. [34]

\section{Conclusion}

Our findings show high rates of poor treatment outcome in this large TB treatment centre. The effect of rural residence on poor TB treatment outcome has implications on current and future interventions. There is a need to more closely monitor rural-dwelling patients accessing care in urban centres and to further decentralise TB care to rural areas including strengthening of community-based TB services in rural areas to improve access to early diagnosis and treatment. Given that HIV services have wider coverage and are better resourced than TB services, facilities providing HIV care in rural communities can expand TB services (diagnosis and treatment) to residents irrespective of their HIV status. This expansion would reduce delays in diagnosis and treatment initiation, and the socio-economic risks and treatment outcome consequences associated with travelling to access care. Ultimately, resource-constrained countries with high burden of TB and HIV as well as other diseases should aim at integrating healthcare and minimise emphasis on vertical programmes. Though tailoring appropriate interventions toward persons at risk of poor treatment outcome may have greater impact on TB control than blanket population-wide interventions, proposed interventions should in addition to individual-level approaches also consider population-based sociocultural and economic contexts. For instance, women empowerment, and girl-child education may be important in northern Nigeria in improving the health status and treatment-seeking behaviour of women and their families. Social protection initiatives which include cash transfers, microfinance credit schemes to improve income-producing activities such as farming, and skills development and capacity building will reduce household poverty and mitigate the impact of unexpected and catastrophic costs of illness on the household. Although TB care coverage is less than satisfactory in many high TBburden countries, it is important that patients with TB that reach the health system get a favourable treatment outcome.

\section{Abbreviations}

AKTH: Aminu Kano Teaching Hospital; ART: Antiretroviral therapy;

CNS: Central nervous system; HIV: Human immunodeficiency virus; LTF: Loss 
to follow-up; PAF: Population attributable fraction; PM: Person-months; RR: Relative risk; TB: Tuberculosis

\section{Acknowledgements}

Not applicable

\section{Funding}

IA is funded by the UK National Institute for Health Research (NIHR), the Medical Research Council (MRC) and Public Health England (PHE)

This study received no specific grant from any funding agency in the public, commercial or not-for-profit sectors.

\section{Availability of data and materials}

The dataset analysed during this study can be made available by the authors with permission from the Research Ethics Committee of Aminu Kano Teaching Hospital as we do not have permission to make data containing HIV status of participants publicly available.

\section{Authors' contributions}

ALA conceptualised the study, acquired the data, performed the analysis, interpreted the data, drafted the initial manuscript, reviewed and revised the manuscript and approved the final manuscript as submitted. IA conceptualised the study, supervised the data analysis and interpretation, critically reviewed and revised the manuscript for important intellectual content and approved the final manuscript as submitted. MHA, NAG, BMM, UML and UB interpreted the results, reviewed and revised the manuscript for important intellectual content and approved the final manuscript as submitted.

\section{Ethics approval and consent to participate}

The study was approved by the Research Ethics Committee of Aminu Kano Teaching Hospital (NHREC/21/08/2008/AKTH/EC/1562). Consent was not required by the committee as data were extracted retrospectively from clinic records.

\section{Consent for publication}

Not applicable

\section{Competing interests}

The authors declare that they have no competing interests.

\section{Publisher's Note}

Springer Nature remains neutral with regard to jurisdictional claims in published maps and institutional affiliations.

\section{Author details}

${ }^{1}$ Department of Community Medicine, College of Health Sciences, Bayero University Kano, Kano, Nigeria. ${ }^{2}$ Department of Community Medicine, Aminu Kano Teaching Hospital, Kano, Nigeria. ${ }^{3}$ Department of Health Policy, Vanderbilt University School of Medicine, Nashville, TN, USA. ${ }^{4}$ Vanderbilt Institute of Global Health, Nashville, TN, USA. ${ }^{5}$ Department of Haematology, Aminu Kano Teaching Hospital, Kano, Nigeria. ${ }^{6}$ Department of Medicine, College of Health Sciences, Bayero University Kano, Kano, Nigeria. ${ }^{7}$ Institute for Global Health, University College London, London, UK.

Received: 10 May 2017 Accepted: 26 December 2017

Published online: 08 January 2018

\section{References}

1. WHO | Global tuberculosis report; 2015. [http://apps.who.int/iris/bitstream/ 10665/191102/1/9789241565059_eng.pdf]

2. Taghizade Moghaddam H, Emami Moghadam Z, Khademi G, Bahreini A, Saeidi M. Tuberculosis: past, present and future. Int J Ped. 2016;4:1243-54.

3. Hargreaves JR, Boccia D, Evans CA, Adato M, Petticrew M, Porter JDH. The social determinants of tuberculosis: from evidence to action. Am J Public Health. 2011;101:654-62.

4. Gomes MG, Barreto ML, Glaziou P, Medley GF, Rodrigues LC, Wallinga J, Squire SB, End TB. Strategy: the need to reduce risk inequalities. BMC Infect Dis. 2016;16:132

5. Uplekar M, Weil D, Lonnroth K, Jaramillo E, Lienhardt C, Dias HM, Falzon D, Floyd K, Gargioni G, Getahun H, et al. WHO's new end TB strategy. Lancet. 2015;385:1799-801.
6. Lönnroth K, Jaramillo E, Williams BG, Dye C, Raviglione M. Drivers of tuberculosis epidemics: the role of risk factors and social determinants. Soc Sci Med. 2009;68:2240-6.

7. Lönnroth K, Raviglione M. The WHO's new end TB strategy in the post-2015 era of the sustainable development goals. Trans R Soc Trop Med Hyg. 2016; 110:148-50.

8. Use of high burden country lists for TB by WHO in the post-2015 era [http://www.who.int/tb/publications/global_report/high_tb_ burdencountrylists2016-2020.pdf?ua=1].

9. $\mathrm{WHO}$ | Global tuberculosis report 2016 [http://apps.who.int/iris/bitstream/ 10665/250441/1/9789241565394-eng.pdf].

10. Nigeria Stop TB Partnership strategic plan 2013-2015 [http://www.stoptb. org/assets/documents/countries/partnerships/Final version Nigeria Stop TB Partnership Strategic Plan.pdf].

11. Otu A. A review of the national tuberculosis and leprosy control programme (ntblcp) of Nigeria: challenges and prospects. Ann Trop Med Pub Health. 2013:6:491-500

12. TB C: April-June 2017 Performance Monitoring Report. 2017.

13. WHO Country TB profile. [ https://extranet.who.int/sree/Reports?op=Replet\&name= \%2FWHO_HQ_Reports\%2FG2\%2FPROD\%2FEXT\%2FTBCountryProfile\&lSO2= NG\&LAN=EN\&outtype=html ].

14. NTBLCP. National Tuberculosis and leprosy control Programme (NTBLCP) 2014 annual report. Nigeria: National Tuberculosis and Leprosy Control Programme; 2014

15. Harling $G$, Ehrlich $R$, Myer $L$. The social epidemiology of tuberculosis in South Africa: a multilevel analysis. Soc Sci Med. 2008;66:492-505.

16. Salaniponi FML, Harries AD, Banda HT, Kang'ombe C, Mphasa N, Mwale A, Upindi B, Nyirenda TE, Banerjee A, Boeree MJ. Care seeking behaviour and diagnostic processes in patients with smear-positive pulmonary tuberculosis in Malawi. Int J Tuberc Lung Dis. 2000:4:327-32.

17. Programme NTaLC: National Tuberculosis and leprosy control Programme (NTBLCP): strategic plan for tuberculosis control in Nigeria : 2006-2010. Federal Ministry of Health, Department of Public Health; 2006.

18. 2011 FMoHoNF:. The National Strategic Plan for TuberculosisandLeprosyControl(2010-2015). Bethesda,MD: HealthSystems20/ 20project, Abt Associateslnc; 18.

19. WHO. Definitions and reporting framework for tuberculosis - 2013 revision (updated December 2014). Geneva, Switzerland: WHO. p. 2013.

20. Ditah IC, Reacher M, Palmer C, Watson JM, Innes J, Kruijshaar ME, Luma HN, Abubakar I. Monitoring tuberculosis treatment outcome: analysis of national surveillance data from a clinical perspective. Thorax. 2008;63:440-6.

21. Abubakar I, Crofts J, Gelb D, Story A, Andrews N, Watson J. Investigating urban-rural disparities in tuberculosis treatment outcome in England and Wales. Epidemiol Infect. 2008;136:122-7.

22. Bangure MG, Mufuta T, Milton C, Notion G. Donewell: trends for tuberculosis treatment outcomes, new sputum smear positive patients in Kwekwe District, Zimbabwe, 2007-2011: a cohort analysis. J Tuberc Res. 2015:03:126.

23. National TB prevalence survey 2012. Nigeria. [http://www.who.int/tb/ publications/NigeriaReport WEB NEW.pdf].

24. Mesfin MM, Newell JN, Madeley RJ, Mirzoev TN, Tareke IG, Kifle YT, Gessessew A, Walley JD. Cost implications of delays to tuberculosis diagnosis among pulmonary tuberculosis patients in Ethiopia. BMC Public Health. 2010:10:173.

25. Gebremariam MK, Bjune GA, Frich JC. Barriers and facilitators of adherence to TB treatment in patients on concomitant TB and HIV treatment: a qualitative study. BMC Public Health. 2010;10:651.

26. Tadesse S. Stigma against tuberculosis patients in Addis Ababa, Ethiopia. PLoS One. 2016;11:e0152900

27. Tola HH, Tol A, Shojaeizadeh D, Garmaroudi G. Tuberculosis treatment non-adherence and lost to follow up among TB patients with or without HIV in developing countries: a systematic review. Iran J Pub Health 2015:44:1-11.

28. Muture BN, Keraka MN, Kimuu PK, Kabiru EW, Ombeka VO, Oguya F. Factors associated with default from treatment among tuberculosis patients in nairobi province, Kenya: a case control study. BMC Public Health 2011:11:696.

29. Jha $\mathrm{V}$. Herbal medicines and chronic kidney disease. Nephrology (Carlton) 2010:15(Suppl 2):10-7.

30. Nwokediuko S, Osuala P, Uduma U, Alaneme A, Onwuka C, Mesigo C. Pattern of liver disease admissions in a Nigerian tertiary hospital. Niger Clin Pract. 2013;16:339-42. 
31. Thinwa J: Indigenous healing practices and their effect on TB and HIV/TB patients' utilization and compliance with anti-TB medication. Ind Study Proj (ISP) Collec 2004, Paper 498.

32. Sonnenberg P, Glynn JR, Fielding K, Murray J, Godfrey-Faussett $P$, Shearer S. How soon after infection with HIV does the risk of tuberculosis start to increase? A retrospective cohort study in south African gold miners. J Infect Dis. 2005;191:150-8.

33. Tweya H, Feldacker C, Phiri S, Ben-Smith A, Fenner L, Jahn A, Kalulu M Weigel R, Kamba C, Banda R, et al. Comparison of treatment outcomes of new smear-positive pulmonary tuberculosis patients by HIV and antiretroviral status in a TB/HIV clinic, Malawi. PLoS One. 2013;8:e56248.

34. Gadoev J, Asadov D, Tillashaykhov M, Tayler-Smith K, Isaakidis P, Dadu A. Colombani pd, Gudmund Hinderaker S, Parpieva N, Ulmasova D, et al: factors associated with unfavorable treatment outcomes in new and previously treated TB patients in Uzbekistan: a five year countrywide study. PLoS One. 2015;10:e0128907.

35. Nglazi MD, Bekker L-G, Wood R, Kaplan R. The impact of HIV status and antiretroviral treatment on TB treatment outcomes of new tuberculosis patients attending co-located TB and ART services in South Africa: a retrospective cohort study. BMC Infect Dis. 2015;15:1-8.

36. Kaplan R, Caldwell J, Middelkoop K, Bekker LG, MMed RW. The impact of ART on TB case fatality stratified by CD4 count for HIV-positive TB patients in cape town, South Africa (2009-2011). J Acquir Immune Defic Syndr. 2014;66:487-94

37. Abdool Karim SS, Naidoo K, Grobler A, Padayatchi N, Baxter C, Gray A, Gengiah T, Nair G, Bamber S, Singh A. Timing of initiation of antiretroviral drugs during tuberculosis therapy. N Engl J Med. 2010;362:697-706.

38. Hargreaves NJ, Kadzakumanja O, Phiri S, Nyangulu DS, Salaniponi FML, Harries AD, Squire SB. What causes smear-negative pulmonary tuberculosis in Malawi, an area of high HIV seroprevalence? Int J Tuberc Lung Dis. 2001; 5:113-22.

39. Gasana M, Vandebriel G, Kabanda G, Tsiouris SJ, Justman J, Sahabo R, Kamugundu D, El-Sadr WM. Integrating tuberculosis and HIV care in rural Rwanda. Int J Tuberc Lung Dis. 2008;12:S39-43.

40. Lima VD, Granich R, Phillips P, Williams B, Montaner JSG. Potential impact of the US President's emergency plan for AIDS relief on the tuberculosis/HIV Coepidemic in selected sub-Saharan African countries. J Infect Dis. 2013;208: 2075-84.

41. Lawn SD, Campbell L, Kaplan R, Little F, Morrow C, Wood R. Delays in starting antiretroviral therapy in patients with HIV-associated tuberculosis accessing non-integrated clinical services in a south African township. BMC Infect Dis. 2011;11:1-9.

42. Nagu TJ, Spiegelman D, Hertzmark E, Aboud S, Makani J, Matee MI, Fawzi W, Mugusi F. Anemia at the initiation of tuberculosis therapy is associated with delayed sputum conversion among pulmonary tuberculosis patients in Dar-es-salaam, Tanzania. PLoS One. 2014;9:e91229.

43. Isanaka S, Mugusi F, Urassa W, Willett WC, Bosch RJ, Villamor E, Spiegelman D, Duggan C, Fawzi WW. Iron deficiency and anemia predict mortality in patients with tuberculosis. J Nutr. 2012;142:350-7.

44. Bates M, Ahmed Y, Kapata N, Maeurer M, Mwaba P, Zumla A. Perspectives on tuberculosis in pregnancy. Int J Infect Dis. 2015;32:124-7.

45. Itogo N, Hill PC, Bissell K, Harries AD, Viney K, Gounder S. Tuberculosis notifications, characteristics and treatment outcomes: urban vs. rural Solomon Islands, 2000\&\#8211;2011. Public Health Action. 2014;4:S25-8.

46. Dangisso MH, Datiko DG, Lindtjørn B. Trends of tuberculosis case notification and treatment outcomes in the Sidama zone, southern Ethiopia: ten-year retrospective trend analysis in urban-rural settings. PLoS One. 2014;9:e114225.

47. Tessema B, Muche A, Bekele A, Reissig D, Emmrich F, Sack U. Treatment outcome of tuberculosis patients at Gondar University teaching hospital, Northwest Ethiopia. A five - year retrospective study. BMC Public Health. 2009;9:371.

48. Ifebunandu NA, Ukwaja KN. Tuberculosis treatment default in a large tertiary care hospital in urban Nigeria: prevalence, trend, timing and predictors. J Infect Public Health. 2012;5:340-5.

49. Gebrezgabiher G, Romha G, Ejeta E, Asebe G, Zemene E, Ameni G. Treatment outcome of tuberculosis patients under directly observed treatment short course and factors affecting outcome in southern Ethiopia: a five-year retrospective study. PLoS One. 2016;11:e0150560.
50. Ukwaja KN, Oshi SN, Alobu I, Oshi DC. Profile and determinants of unsuccessful tuberculosis outcome in rural Nigeria: implications for tuberculosis control. World J Methodol. 2016;6:118-25.

51. Andrews JR, Basu S, Dowdy DW, Murray MB. The epidemiological advantage of preferential targeting of tuberculosis control at the poor. Int J Tuberc Lung Dis. 2015;19:375-80.

52. Sawadogo B, Tint KS, Tshimanga M, Kuonza L, Ouedraogo L. Risk factors for tuberculosis treatment failure among pulmonary tuberculosis patients in four health regions of Burkina Faso, 2009: case control study. Pan Afr Med J. 2015;21:152.

53. Panjabi R, Comstock GW, Golub JE. Recurrent tuberculosis and its risk factors: adequately treated patients are still at high risk. Int J Tuberc Lung Dis. 2007;11:828-37.

\section{Submit your next manuscript to BioMed Central and we will help you at every step:}

- We accept pre-submission inquiries

- Our selector tool helps you to find the most relevant journal

- We provide round the clock customer support

- Convenient online submission

- Thorough peer review

- Inclusion in PubMed and all major indexing services

- Maximum visibility for your research

Submit your manuscript at www.biomedcentral.com/submit 